\title{
Development and Validation of a Health Needs Assessment Scale for Primary Liver Cancer Patients Receiving Surgical Management
}

\author{
Quan Jiang ${ }^{1}$, Yu Wang ${ }^{2}$, Rui Xi ${ }^{3}$, Xiaolan Wang, ${ }^{1, *}$ \\ ${ }^{1}$ Department of Hepatobiliary Surgery, The First Affiliated Hospital of Jinan University, Guangzhou, China \\ ${ }^{2}$ Department of Infectious, The First Affiliated Hospital of Jinan University, Guangzhou, China \\ ${ }^{3}$ Department of Gastroenterology, The First Affiliated Hospital of Jinan University, Guangzhou, China
}

Email address:

151733060@qq.com (Quan Jiang), wangxiaoLan74@126.com (Xiaolan Wang)

${ }^{*}$ Corresponding author

To cite this article:

Quan Jiang, Yu Wang, Rui Xi, Xiaolan Wang. Development and Validation of a Health Needs Assessment Scale for Primary Liver Cancer Patients Receiving Surgical Management. International Journal of Clinical Oncology and Cancer Research. Vol. 6, No. 2, 2021 , pp. 90-97. doi: $10.11648 /$ j.ijcocr.20210602.15

Received: May 22, 2021; Accepted: June 3, 2021; Published: June 16, 2021

\begin{abstract}
Cancer survivors usually have varying degrees of physical and psychosocial issues and poor quality of life. Understanding the health needs from a patient's view is necessary for developing targeted supportive services. There is neither research on the postoperative health needs of primary liver cancer (PLC) patients, nor the assessment tools specifically designed for PLC patients. The purpose of this study was to develop a postoperative health needs assessment scale for PLC patients receiving surgical management. This was a methodological instrument validation study conducted in the first affiliated of Jinan University between August 2018 and December 2019. PLC patients receiving surgical management were selected by convenient sampling methods. Ten patients were selected for semi-structured in-depth interviews to generate a 50 -item initial scale. After two rounds of expert consultation, a 44-item initial scale was used for a 20-respondent small sample pre-test. The pre-survey scale was distributed to 250 patients. Structural validity was examined with factor analysis, and reliability was evaluated with the Cronbach alpha and split-half reliability. Among the 250 respondents of the pre-survey scale, 232 cases completed the questionnaire. After item analysis and factor analysis, 38 items were kept in the final scale. The content validity index for the whole scale (S-CVI) and each item (I-CVI) was 0.90 and 0.80-0.90, respectively. The total Cronbach alpha value was 0.935, and the split-half reliability was 0.931 . The healthy needs assessment scale for PLC patients receiving surgical management has good reliability and validity.
\end{abstract}

Keywords: Primary Liver Cancer (PLC), Healthy Needs, Measurement Scale, Reliability, Validity

\section{Introduction}

Primary liver cancer (PLC) is one of the leading cancers worldwide [1], as well as the fourth most common malignant tumor and the third most common cause of cancer-associated death in China [2, 3]. Due to the insidious onset, early asymptomatic, and rapid progress, PLC is usually at the locally advanced stage or has distant metastasis at the time of diagnosis, resulting in a poor prognosis [4]. In recent years, due to early detection and advances in treatment technology, the survival of PLC patients exhibits an increasing trend worldwide [5]. According to a large study with patients from
28 countries [5], the pooled estimate of age-standardized five-year net survival for liver cancer increases from $11.0 \%$ (1995-2000) to 14.8\% (2004-2009). In China, the 5-year net survival rate was markedly elevated from $2.7 \%$ (1995-2000) to $19.5 \%$ (2004-2009) [5].

Cancer survivors usually have varying degrees of physical and psychosocial issues [6,7], leading to a worse quality of life (QoL) as compared with healthy individuals [8]. To improve cancer survivor's QoL, it is necessary to understand the health needs from a patient's view to develop targeted supportive services [9]. Research on the unmet needs of cancer survivors has been conducted in a variety of cancer types, such as breast 
cancer [10], colorectal cancer [11], lung cancer [12], prostate cancer [13] bladder cancer [14]. However, the unmet needs of PLC survivors have not been investigated. In China, only a few studies have investigated the unmet needs of cancer survivors [15-19], but the assessment tools used are not designed targeting PLC survivors. At present, there is no standardized quantitative postoperative health needs assessment tool for PLC patients worldwide. Thus, increasing PLC survivors requires a validated needs assessment tool. The purpose of this study was to develop a postoperative health needs assessment scale for PLC patients receiving surgical management.

\section{Methods}

\subsection{Study Design and Setting}

This was a methodological instrument validation study conducted in the first affiliated of Jinan University between August 2018 and December 2019. This study was approved by the ethical review boards of our hospital.

\subsection{Study Subjects}

For all study subjects of this study, patients with PLC receiving surgical management were selected by convenient sampling methods in the first affiliated of Jinan University between August 2018 and December 2019. Inclusion criteria were: (1) patients receiving resection surgical management; (2) Pathological diagnosis of PLC; (3) aged 18-65 years; (4) education level was elementary school or above; (5) Signed informed consent form. Exclusion criteria included: (1) Combined with other tumors; (2) Combined with severe heart, brain, lung, kidney diseases, or other serious infectious diseases; (3) A history of mental disease and taking psychiatric drugs; (4) Unable to communicate or unconscious.

\subsection{Semi-structured In-Depth Interview}

To create the item pool of the questionnaire, a liver disease specialist team (3 chief physicians, 1 chief nurse, 1 deputy chief nurse, 1 chief nurse, 2 nurses, and 2 graduate students) was established to build a semi-structured interview outline based on relevant literature research [20-23]. Ten PLC patients receiving surgical management were selected for semi-structured in-depth interviews. Then a 7-step Colaizzi qualitative data analysis method was used to organize the interview results and generate 50 original scale items [24].

\subsection{Experts Evaluation on the Effectiveness and Importance of the Scale Items}

Ten experts who were familiar with scale building and had more than ten years of experience in the field of liver cancer clinical treatment, nursing or education, bachelor degree or above, and intermediate professional titles or above were invited to conduct two rounds of evaluation on the effectiveness and importance of the scale items. Six out of 50 items with low importance were deleted and an initial scale of 44 items was generated.

\subsection{Small Sample Pre-test}

The initial scale was distributed to 20 PLC patients receiving surgical management to conduct a small sample pre-test. The content of the initial scale, such as the language used, ease of understanding, the order of the scale items, were evaluated based on the completed questionnaires. After which, a pre-survey scale was generated with the modified items.

\subsection{The Pre-survey Scale}

After explaining the research and the confidentiality agreement, the pre-survey scale was distributed to 250 patients. The questionnaire was mainly self-filled by the patients. For those unable to complete the questionnaire independently due to educational or physical reasons, the investigators would help fill it out. The questionnaire should be completed at least above 240 seconds to ensure the quality. The investigators would check on the completeness when patients completed the questionnaire. All items on the questionnaire were set as "mandatory questions" to ensure the completeness of the questionnaire.

\subsection{Item Selection}

The item analysis and critical ratio methods were used to select items of the pre-survey scale. According to subjects' total score of all items, the lower $27 \%$ of the rankings were low score group ( $\leq 163$ points), while the top $27 \%$ were high score group ( $\geq 184$ points). T-test was used to compare the item score between the two groups, and items with a $\mathrm{T}$ value greater than 3 and $\mathrm{P}<0.05$ were kept.

\subsection{The Validity and Reliability of the Scale}

The item content validity index (I-CVI) and scale content validity index (S-CVI) were used to evaluate the validity. Structural validity was examined with factor analysis. The principal component analysis was used to extract factors with character value great than 1. Exploratory factor analysis of the items was performed by maximum variance (varimax) orthogonal rotation. The factor extraction was based on eigenvalue $>1$. Items with a common degree of less than 0.2 or factor load less than 0.4 were deleted. Lastly, the confirmatory factor analysis of the four dimensions was performed based on the exploratory factor analysis.

Cronbach's $\alpha$ coefficient and half-reliability index were used for the reliability test. The internal consistency of the reliability assessment of the scale refers to the homogeneity between the items of the scale.

\subsection{Statistical Analysis}

All analyses were done using IBM SPSS Version 25 (SPSS Statistics V25, IBM Corporation, Somers, New York). Categorical variables were expressed by frequency $(\mathrm{N})$ and percentage $(\%)$, and continuous variables were expressed with mean and standard deviation (SD). Item analysis was used to report the psychometrical properties of each item, including mean (item difficulty), SD (item discrimination), correlation to 
a total score, low and high sub-group difference, and item-deleted Cronbach's alpha. Exploratory factor analysis, content validity index, and the Cronbach's $\alpha$ coefficient of each dimension as well as total scale were used to evaluate the structural validity, content validity, and internal consistency reliability of the scale, respectively. The statistical significance level for all the tests was set at a $\mathrm{P}<0.05$, two-tailed.

\section{Results}

\subsection{Expert Consultation Results}

Ten PLC patients receiving surgical management were selected for semi-structured in-depth interviews, and 50 original scale items were generated. For evaluating the 50 scale items, questionnaires were distributed to 10 experts for the first and second rounds of expert consultation, respectively. All the questionnaires were completed and returned, with the authoritative coefficients of 0.830 and 0.835 , and Kendall coordination coefficients of 0.247 and 0.357 .

Two rounds of expert consultation concluded that the importance score of all items ranged between 3.80-5.00, and the items' coefficient of variation was 0-33\%. After expert consultation and discussion, 6 items (item number 16, 17, 18, 19, $20,35)$ were deleted (Table 1), which were considered unable to reflect the specific postoperative health needs of PLC patients, such as "Do you need assistance with eating, dressing, washing".
As a result, 44 items were included in the initial scale.

\subsection{Results of Small Sample Pre-test}

The initial scale was distributed to 20 PLC patients receiving surgical management to conduct a small sample pre-test. According to the recommendations of the 20 respondents, two items were rephrased and 1 item order in the initial scale was revised to generate the pre-survey scale. For instance, the wording "Do you need long-term bed rest?" was rephrased to "Do you need to deal with the discomfort from prolonged bed rest?". The last item "do you wish you can face the disease positively" in the psychological needs section was moved to the first item, while the original first item "do you need to face the pain and fear from the disease" automatically became the second item.

\subsection{The Demographic Characteristics of Respondents in the Pre-survey}

Among the 250 respondents, 232 cases (215 males, 17 females, mean age $=50.54 \pm 11.07$ years, range: 19 to 78 ) completed the survey. Patients' demographic characteristics were summarized in Table 2. Of them, 214 (92.24\%) cases were married, and $211(90.95 \%)$ cases had medical insurance. 112 (48.28\%) cases had a junior high school education or below, and $120(51.72 \%)$ had a high school education or above.

Table 1. Summary of item selection and deletion.

\begin{tabular}{|c|c|c|c|c|c|c|c|c|c|}
\hline & Expert validi & & & & & & & & \\
\hline Item & $\begin{array}{l}\text { Rating score } \\
(\text { mean } \pm \text { SD })\end{array}$ & $\begin{array}{l}\text { Coefficient } \\
\text { of variation }\end{array}$ & $\begin{array}{l}\text { Full-score } \\
\%\end{array}$ & Mean & SD & $\begin{array}{l}\text { Item-total } \\
\text { correlation }\end{array}$ & $\begin{array}{l}\text { P of high-low } \\
\text { group t-test }\end{array}$ & $\begin{array}{l}\text { Item-deleted } \\
\text { Cronbach's alpha }\end{array}$ & $\begin{array}{l}\text { Reason for } \\
\text { item deletion }\end{array}$ \\
\hline 1 & $4.90 \pm 0.32$ & 0.06 & $90 \%$ & 4.50 & 0.93 & 0.64 & $<0.001$ & - & - \\
\hline 2 & $5.00 \pm 0.00$ & 0.00 & $100 \%$ & 4.22 & 1.03 & 0.76 & $<0.001$ & - & - \\
\hline 3 & $4.80 \pm 0.42$ & 0.09 & $80 \%$ & 4.39 & 0.97 & 0.70 & $<0.001$ & - & - \\
\hline 4 & $4.80 \pm 0.63$ & 0.13 & $90 \%$ & 4.03 & 1.04 & 0.41 & $<0.001$ & - & - \\
\hline 5 & $4.60 \pm 0.52$ & 0.11 & $60 \%$ & 4.14 & 1.10 & 0.51 & $<0.001$ & - & - \\
\hline 6 & $4.50 \pm 0.71$ & 0.16 & $60 \%$ & 4.04 & 1.11 & 0.59 & $<0.001$ & - & - \\
\hline 7 & $4.20 \pm 1.03$ & 0.25 & $50 \%$ & 4.12 & 1.08 & 0.61 & $<0.001$ & - & - \\
\hline 8 & $4.20 \pm 0.79$ & 0.19 & $40 \%$ & 4.03 & 1.11 & 0.74 & $<0.001$ & - & - \\
\hline 9 & $4.20 \pm 0.79$ & 0.19 & $40 \%$ & 3.90 & 0.69 & 0.06 & 0.156 & Increased & High-low t-test \\
\hline 10 & $4.50 \pm 0.97$ & 0.22 & $70 \%$ & 4.41 & 0.91 & 0.65 & $<0.001$ & - & - \\
\hline 11 & $4.70 \pm 0.48$ & 0.10 & $70 \%$ & 4.17 & 1.09 & 0.72 & $<0.001$ & - & - \\
\hline 12 & $4.70 \pm 0.48$ & 0.10 & $70 \%$ & 3.00 & 0.95 & 0.25 & $<0.001$ & Increased & - \\
\hline 13 & $4.60 \pm 0.70$ & 0.15 & $70 \%$ & 2.56 & 0.97 & 0.30 & 0.003 & - & - \\
\hline 14 & $4.60 \pm 0.70$ & 0.15 & $70 \%$ & 3.07 & 1.15 & -0.09 & $<0.001$ & Increased & - \\
\hline 15 & $4.90 \pm 0.32$ & 0.06 & $90 \%$ & 2.37 & 1.29 & -0.39 & $<0.001$ & Increased & - \\
\hline 16 & $4.20 \pm 1.32$ & 0.31 & $60 \%$ & 3.74 & 1.25 & 0.27 & 0.002 & Increased & $\begin{array}{l}\text { Expert } \\
\text { suggestion }\end{array}$ \\
\hline 17 & $3.80 \pm 1.14$ & 0.30 & $30 \%$ & 1.81 & 1.04 & 0.01 & 0.099 & Increased & $\begin{array}{l}\text { Expert } \\
\text { suggestion }\end{array}$ \\
\hline 18 & $4.00 \pm 1.05$ & 0.26 & $40 \%$ & 2.41 & 0.92 & -0.02 & 0.649 & Increased & $\begin{array}{l}\text { Expert } \\
\text { suggestion }\end{array}$ \\
\hline 19 & $3.80 \pm 1.03$ & 0.27 & $30 \%$ & 2.59 & 1.02 & -0.11 & 0.235 & Increased & $\begin{array}{l}\text { Expert } \\
\text { suggestion }\end{array}$ \\
\hline 20 & $3.90 \pm 1.29$ & 0.33 & $50 \%$ & 3.77 & 0.69 & 0.49 & $<0.001$ & - & $\begin{array}{l}\text { Expert } \\
\text { suggestion }\end{array}$ \\
\hline 21 & $4.90 \pm 0.32$ & 0.06 & $90 \%$ & 4.09 & 1.08 & 0.56 & $<0.001$ & - & - \\
\hline 22 & $4.80 \pm 0.42$ & 0.09 & $80 \%$ & 3.99 & 1.18 & 0.50 & $<0.001$ & - & - \\
\hline 23 & $4.50 \pm 0.53$ & 0.12 & $50 \%$ & 3.71 & 1.34 & 0.76 & $<0.001$ & - & - \\
\hline 24 & $4.20 \pm 0.63$ & 0.15 & $30 \%$ & 3.10 & 0.80 & 0.41 & $<0.001$ & - & - \\
\hline 25 & $4.70 \pm 0.68$ & 0.14 & $80 \%$ & 3.27 & 0.93 & 0.79 & $<0.001$ & - & - \\
\hline 26 & $4.70 \pm 0.48$ & 0.10 & $70 \%$ & 3.49 & 1.00 & 0.41 & $<0.001$ & - & - \\
\hline
\end{tabular}




\begin{tabular}{llllllllll}
\hline & Expert validity & & & & & & \\
Item & $\begin{array}{l}\text { Rating score } \\
\text { (mean } \pm \text { SD) }\end{array}$ & $\begin{array}{l}\text { Coefficient } \\
\text { of variation }\end{array}$ & $\begin{array}{l}\text { Full-score } \\
\text { \% }\end{array}$ & Mean & SD & $\begin{array}{l}\text { Item-total } \\
\text { correlation }\end{array}$ & $\begin{array}{l}\text { P of high-low } \\
\text { group t-test }\end{array}$ & $\begin{array}{l}\text { Item-deleted } \\
\text { Cronbach's alpha }\end{array}$ & $\begin{array}{l}\text { Reason for } \\
\text { item deletion }\end{array}$ \\
\hline 27 & $4.50 \pm 0.53$ & 0.12 & $50 \%$ & 2.43 & 0.82 & 0.02 & 0.508 & Increased & High-low t-test \\
28 & $4.60 \pm 0.97$ & 0.21 & $80 \%$ & 3.01 & 1.16 & 0.83 & $<0.001$ & - & - \\
29 & $4.70 \pm 0.48$ & 0.10 & $70 \%$ & 3.09 & 1.15 & 0.82 & $<0.001$ & - & - \\
30 & $4.50 \pm 0.53$ & 0.12 & $50 \%$ & 2.78 & 1.05 & 0.71 & $<0.001$ & - & - \\
31 & $4.60 \pm 0.52$ & 0.11 & $60 \%$ & 2.48 & 0.97 & 0.00 & 0.982 & Increased & High-low t-test \\
32 & $4.30 \pm 0.82$ & 0.19 & $50 \%$ & 2.66 & 1.11 & 0.03 & 0.505 & Increased & High-low t-test \\
33 & $4.60 \pm 0.52$ & 0.11 & $60 \%$ & 2.85 & 1.09 & 0.72 & $<0.001$ & - & - \\
34 & $4.50 \pm 0.53$ & 0.12 & $50 \%$ & 4.03 & 1.08 & 0.08 & 0.994 & Increased & High-low t-test \\
35 & $4.00 \pm 0.67$ & 0.17 & $20 \%$ & 4.57 & 0.72 & 0.78 & $<0.001$ & - & Expert \\
36 & $4.70 \pm 0.48$ & 0.10 & $70 \%$ & 4.70 & 0.52 & 0.60 & $<0.001$ & - & suggestion \\
37 & $4.40 \pm 0.70$ & 0.16 & $50 \%$ & 4.47 & 0.68 & 0.63 & $<0.001$ & - & - \\
38 & $4.50 \pm 0.53$ & 0.12 & $50 \%$ & 4.61 & 0.61 & 0.69 & $<0.001$ & - & - \\
39 & $4.30 \pm 0.68$ & 0.16 & $40 \%$ & 4.49 & 0.78 & -0.38 & $<0.001$ & Increased & - \\
40 & $5.00 \pm 0.00$ & 0.00 & $100 \%$ & 4.48 & 0.74 & 0.70 & $<0.001$ & - & EFA \\
41 & $4.60 \pm 0.52$ & 0.11 & $60 \%$ & 4.54 & 0.73 & 0.71 & $<0.001$ & - & - \\
42 & $4.90 \pm 0.32$ & 0.06 & $90 \%$ & 4.55 & 0.74 & 0.64 & $<0.001$ & - & - \\
43 & $4.90 \pm 0.32$ & 0.06 & $90 \%$ & 4.68 & 0.56 & 0.54 & $<0.001$ & - & - \\
44 & $4.90 \pm 0.32$ & 0.06 & $90 \%$ & 4.69 & 0.52 & 0.50 & $<0.001$ & - & - \\
45 & $4.80 \pm 0.42$ & 0.09 & $80 \%$ & 4.73 & 0.52 & 0.59 & $<0.001$ & - & - \\
46 & $4.80 \pm 0.42$ & 0.09 & $80 \%$ & 4.71 & 0.58 & 0.39 & $<0.001$ & - & - \\
47 & $4.90 \pm 0.32$ & 0.06 & $90 \%$ & 4.58 & 0.77 & 0.64 & $<0.001$ & - & - \\
48 & $4.90 \pm 0.32$ & 0.06 & $90 \%$ & 4.64 & 0.57 & 0.70 & $<0.001$ & - & - \\
49 & $4.50 \pm 0.53$ & 0.12 & $50 \%$ & 4.71 & 0.50 & 0.60 & $<0.001$ & - & - \\
50 & $4.80 \pm 0.42$ & 0.09 & $80 \%$ & 4.70 & 0.50 & 0.62 & $<0.001$ & - & - \\
\hline & & & & & & & & & - \\
\end{tabular}

Table 2. Patients demographic characteristics.

\begin{tabular}{|c|c|}
\hline Parameters & N (\%) \\
\hline \multicolumn{2}{|l|}{ Gender } \\
\hline Male & $215(92.67 \%)$ \\
\hline Female & $17(7.33 \%)$ \\
\hline Age, year & $50.54 \pm 11.07$ \\
\hline $18-45$ & $56(24.14 \%)$ \\
\hline $46-59$ & $122(52.59 \%)$ \\
\hline 60 and above & $54(23.28 \%)$ \\
\hline \multicolumn{2}{|l|}{ Employment } \\
\hline Retired & $14(6.03 \%)$ \\
\hline Office worker & $56(24.14 \%)$ \\
\hline Farmer & $40(17.24 \%)$ \\
\hline Freelancer & $25(10.78 \%)$ \\
\hline Unemployed & $97(41.81 \%)$ \\
\hline \multicolumn{2}{|l|}{ Marriage status } \\
\hline Married & 214 (92.24\%) \\
\hline Single & $18(7.76 \%)$ \\
\hline \multicolumn{2}{|l|}{ Educational level } \\
\hline Junior high school and below & $112(48.28 \%)$ \\
\hline Senior high school and above & $120(51.72 \%)$ \\
\hline \multicolumn{2}{|l|}{ Annual income } \\
\hline$<30,000$ & $140(60.34 \%)$ \\
\hline $30,000-80,000$ & $65(28.02 \%)$ \\
\hline $80,001-30,000$ & $27(11.64 \%)$ \\
\hline \multicolumn{2}{|l|}{ Living region } \\
\hline City & $154(66.38 \%)$ \\
\hline Village & $78(33.62 \%)$ \\
\hline \multicolumn{2}{|l|}{ Payment of medical expenditure } \\
\hline Medical insurance & $211(90.95 \%)$ \\
\hline Business insurance & $19(8.19 \%)$ \\
\hline At own expense & $2(0.86 \%)$ \\
\hline
\end{tabular}

\subsection{Pre-survey Scale Results}

A total of 250 questionnaires were distributed and 232 valid questionnaires were completed, with an effective completion rate of $92.80 \%$. During item analysis, 5 items (item number 9, 27, 31, 32, 34) with an insignificant difference in the total score between the high and low group $(P>0.05)$ and poor discrimination $(t<3)$ were deleted, and 39 
items were kept. The detailed item analysis results were demonstrated in Table 1, including mean (difficulty), SD (item discrimination), item-total correlation, and item-deleted Cronbach's alpha.

\subsection{Content Validity and Structural Validity}

The content validity index for the scale (S-CVI) was 0.90 , and the content validity index of each item (I-CVI) ranged between 0.80-0.90.

Table 3. Results of exploratory factor analysis.

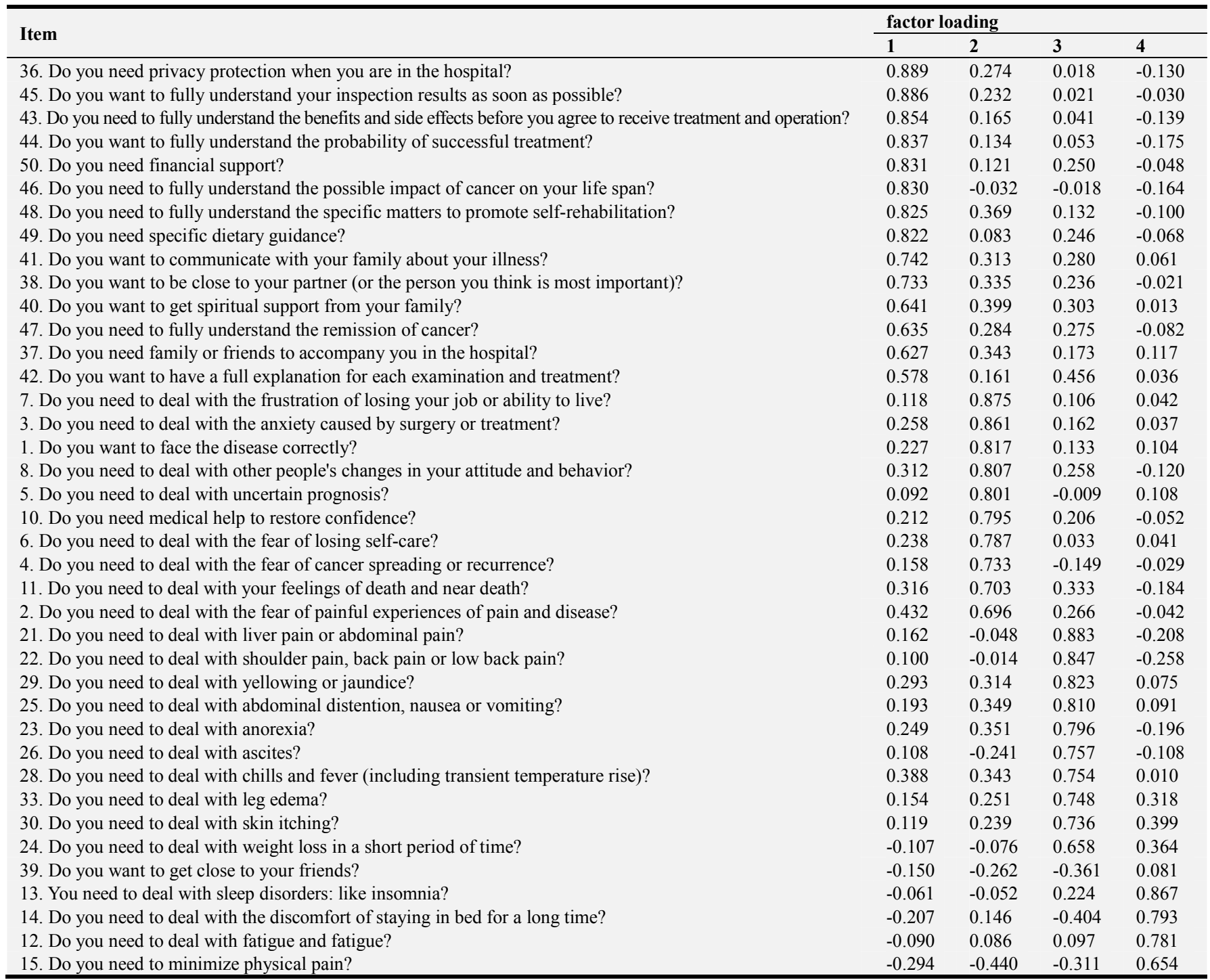

Scree Plot

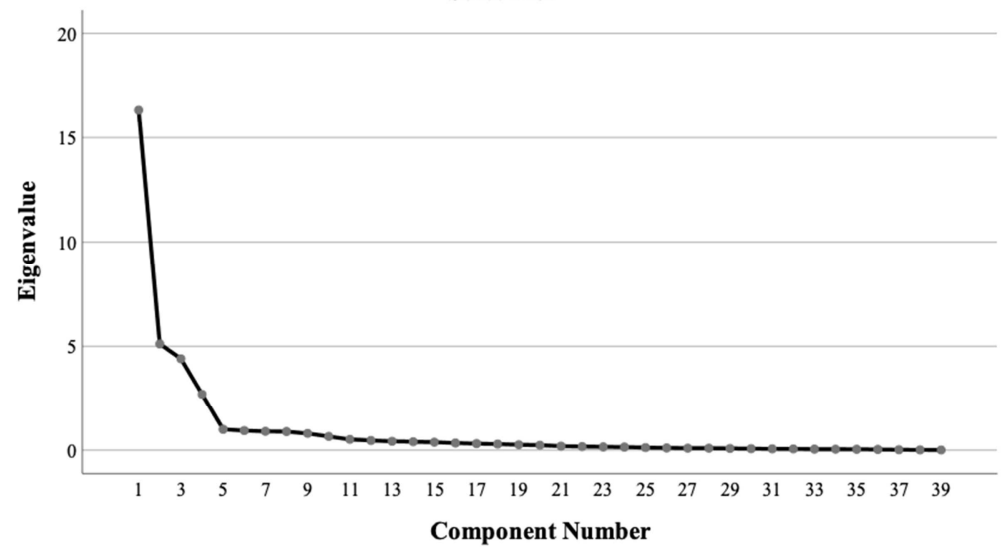

Figure 1. Scree plot of factor analysis of postoperative health demand scale in patients with PLC. 
Structural validity was examined with factor analysis. The health needs assessment scale met the requirements of factor analysis with a Kaiser-Meyer-Olkin (KMO) statistic of 0.899 and $P$ less than 0.05 . The first-factor analysis showed that the common degree of the 39 items was greater than 0.2 and the factor load was all greater than or equal to 0.4 . The principal component analysis was used to extract factors with character value great than 1. Exploratory factor analysis of the items was performed by maximum variance orthogonal rotation (Table 3 ). The scree plot (Figure 1) showed that the trend becomes flat after the 5th factor, 4 common factors with eigenvalue $>1$ were selected with a cumulative explanatory variance of $73.251 \%$.

Item 39 had a factor load of less than 0.5 in each dimension, indicating that it was an invalid item and should be deleted. The exploratory factor analysis was performed again after the deletion and a final scale with 4 dimensions and 38 items were generated.

\subsection{Reliability Test}

The measurement cannot be repeated within 2 to 4 weeks due to the high mobility of the inpatients and short hospital stay. Thereby no reproducibility test was performed. The Cronbach's $\alpha$ coefficient for the final scale was 0.935 , with an $\alpha$ coefficient of $0.952,0.826,0.945,0.958$ in four dimensions, respectively. After the odd-even splitting, the half-reliability of the scale was 0.931 .

\section{Discussion}

China has the highest incidence of PLC in the world, accounting for about $50 \%$ of global PLC cases [25]. Approximately 422,000 Chinese patients die from PLC each year, accounting for $30 \%$ of the total global PLC deaths [2, 3]. Cancer survivors usually have varying degrees of physical and psychosocial issues $[6,7]$ as well as poor QoL. However, due to poor prognosis, short postoperative survival time the various complications associated with PLC, the medical team and the patient's family pay more attention to the disease itself, rather than the social and psychological needs of the patient. Assessing patient's needs for help on given issues from the patient's own perspective can allocate limited medical care resources to patient's issues most in need of solution. In addition, understanding these unmet needs may help to develop targeted interventions [26]. Currently, there is a lack of research on the health needs of PLC patients and a lack of targeted assessment tools to measure postoperative health needs of PLC patients worldwide. Therefore, it is urgently required to develop a measurement tool for the postoperative health needs of PLC patients.

To develop this assessment scale, in this study, the item pool of the scale was drafted based on extensive reference to relevant literature, followed by the semi-structured in-depth interviews with PLC patients respondents. The scale items were further revised according to the experts' opinions and the results of the small sample pre-test, which generated more scientifically valid and rigorous content. Critical ratio method and item analysis were performed for item selection. Following the reliability and validity tests, a final scale with 4 dimensions and 38 items were generated. To our best knowledge, this is the first study developing a targeted scale to measure the health needs of PLC patients receiving surgical management.

The content validity index for the whole scale (S-CVI) and each item (I-CVI) was 0.90 and 0.80-0.90, respectively. Both $\mathrm{S}-\mathrm{CVI}$ and I-CVI were higher than the reference value (0.9 and 0.8) [27], indicating that the scale has sufficient content validity and can reflect the overall health needs of PLC patients. The factor analysis showed that the scale had a common degree greater than 0.2 and the factor load of all items was greater than or equal to 0.4 . Four common factors with a cumulative variance of $73.251 \%$ were extracted from the gravel map. The four common factors included physiological status, psychological status, additional symptoms of PLC, and social support, which meets the theoretical framework of the scale and covers all aspects of the health needs of PLC patients.

The scale reliability was assessed by internal consistency and half-reliability analysis. The scale was considered internally consistent with the Cronbach's $\alpha$ coefficient of the total scale greater than 0.8 and the Cronbach's $\alpha$ coefficient of each dimension greater than 0.6 . The half-reliability index was also one of the indicators that reflect the internal consistency of the scale. A half-reliability index greater than or equal to 0.8 indicates an internally consistent scale [28]. In the developed scale in the current study, he Cronbach's $\alpha$ coefficients of the scale and four dimensions were 0.935 and 0.826-0.958, respectively. The half-reliability index of the scale after the odd-even splitting was 0.931 . These results suggested that the scale had high internal consistency and could be used to measure patients' real needs. This scale can help clinical nurses or home caregivers understand the health needs of PLC patients, providing targeted interventions to improve patient's QoL.

Cancer Survivors' Unmet Needs measure (CaSUN) is a scale frequently used to assess the unmet needs of cancer survivors in a verity of cancer types [29-32]. The CaSUN is a general scale and could be used for a verity of cancer types. By contrast, the health needs scale described in the current study was developed based on the relevant literature on the postoperative health needs of PLC patients. Compared to the general scale, our targeted scale can be used to more specifically measure the physical and psychosocial issues of PCL patients. For instance, our targeted scale included the questions "Do you need to deal with liver pain or abdominal pain?", "Do you need to deal with sleep disorders: such as insomnia?", which are the specific questions for PLC patients that does not exist in the comprehensive scales (such as CaSUN).

There are still some limitations to this study. First, only 10 experts from Guangdong were invited for consultation, and all subjects included in the study were selected from a single hospital. In addition, the applicability and user satisfaction of the scale were not evaluated due to time constraints. Moreover, we did not use an external cohort to perform the reliability and 
validity tests. Due to the limited sample size, the clinical reference value calculated from the scale may not be accurate enough. In the future, a well-designed, large multi-center study should be conducted to validate the findings of this study.

\section{Conclusion}

A postoperative health needs assessment scale for PLC patients receiving surgical management was generated, containing 38 items within 4 dimensions. The scale has been confirmed to be reliable and valid, and can be used to evaluate the postoperative health needs of PLC patients by clinical nurses or home caregivers. In the future, multi-center and large sample research will be conducted in different regions, and at the same time, the use and satisfaction of the scale will be investigated, so as to obtain more real and effective data and further improve the scale.

\section{Funding}

Supported by the Nursing research project of Guangdong Nursing Association (gdhlxueh2019zx 343).

\section{Declaration of Competing Interest}

All the authors do not have any possible conflicts of interest.

\section{References}

[1] Ferlay J, Colombet M, Soerjomataram I, Mathers C, Parkin DM, Piñeros M, Znaor A \& Bray F. Estimating the global cancer incidence and mortality in 2018: GLOBOCAN sources and methods. Int J Cancer. 2019; 144 (8): 1941-1953.

[2] Bray F, Ferlay J, Soerjomataram I, Siegel RL, Torre LA \& Jemal A. Global cancer statistics 2018: GLOBOCAN estimates of incidence and mortality worldwide for 36 cancers in 185 countries. CA Cancer J Clin. 2018; 68 (6): 394-424.

[3] Chen W, Zheng R, Baade PD, Zhang S, Zeng H, Bray F, Jemal A, Yu XQ \& He J. Cancer statistics in China, 2015. CA Cancer J Clin. 2016; 66 (2): 115-132.

[4] Correnti M, Booijink R, Di Maira G, Raggi C \& Marra F. Stemness features in liver cancer. Hepatoma Res. 2018; 4 (11): 69.

[5] Bannon F, Di Carlo V, Harewood R, Engholm G, Ferretti S, Johnson CJ, Aitken JF, Marcos-Gragera R, Bonaventure A, Gavin A, Huws D, Coleman MP \& Allemani C. Survival trends for primary liver cancer, 1995-2009: analysis of individual data for 578,740 patients from 187 population-based registries in 36 countries (CONCORD-2). Ann Cancer Epidemiol. 2019; 36.

[6] Gordon LG, Merollini KMD, Lowe A \& Chan RJ. A Systematic Review of Financial Toxicity Among Cancer Survivors: We Can't Pay the Co-Pay. Patient. 2017; 10 (3): 295-309.

[7] Moser EC \& Meunier F. Cancer survivorship: A positive side-effect of more successful cancer treatment. Eur J Cancer, Suppl. 2014; 12 (1): 1-4.
[8] Weaver KE, Forsythe LP, Reeve BB, Alfano CM, Rodriguez JL, Sabatino SA, Hawkins NA \& Rowland JH. Mental and physical health-related quality of life among U.S. cancer survivors: population estimates from the 2010 National Health Interview Survey. Cancer Epidemiol Biomarkers Prev. 2012; 21 (11): 2108-17.

[9] Lo WT, Yates P \& Chan RJ. Unmet supportive care needs and symptom burden in Taiwanese cancer survivors who have completed primary treatment. Eur J Oncol Nurs. 2018; 357984.

[10] Fang SY, Cheng HR \& Lin CY. Validation of the modified Chinese Cancer Survivor's Unmet Needs (CaSUN-C) for women with breast cancer. Psychooncology. 2018; 27 (1): $236-242$.

[11] Sodergren SC, Wheelwright SJ, Permyakova N V, Patel M, Calman L, Smith PWF, Din A, Richardson A, Fenlon D, Winter J, Corner J, Foster C \& Members of Study Advisory Committee. Supportive care needs of patients following treatment for colorectal cancer: risk factors for unmet needs and the association between unmet needs and health-related quality of life-results from the ColoREctal Wellbeing (CREW) study. J Cancer Surviv. 2019; 13 (6): 899-909.

[12] Yun YH, Shon E-J, Yang A-J, Kim SH, Kim YA, Chang YJ, Lee J, Kim MS, Lee H-S, Zo JI, Kim J, Choi YS \& Shim YM. Needs regarding care and factors associated with unmet needs in disease-free survivors of surgically treated lung cancer. Ann Oncol Off J Eur Soc Med Oncol. 2013; 24 (6): 1552-9.

[13] Mazariego CG, Juraskova I, Campbell R \& Smith DP. Long-term unmet supportive care needs of prostate cancer survivors: 15-year follow-up from the NSW Prostate Cancer Care and Outcomes Study. Support Care Cancer. 2020, 28 (11): 5511-5520.

[14] Mohamed NE, Pisipati S, Lee CT, Goltz HH, Latini DM, Gilbert FS, Wittmann D, Knauer CJ, Mehrazin R, Sfakianos JP, McWilliams GW, Quale DZ \& Hall SJ. Unmet informational and supportive care needs of patients following cystectomy for bladder cancer based on age, sex, and treatment choices. Urol Oncol. 2016; 34 (12): 531. e7-531. e14.

[15] Li Q, Xu Y, Lin Y, Li J, Huang W \& Chen Y. Psychometric properties of the Chinese version of the cancer survivors' unmet needs measure. Eur J Oncol Nurs. 2020; 46101772.

[16] Lou Y, Yates P, Chan RJ, Ni X, Hu W, Zhuo S \& Xu H. Unmet Supportive Care Needs and Associated Factors: a Cross-sectional Survey of Chinese Cancer Survivors. J Cancer Educ. 2020 (1).

[17] So WKW, Chow KM, Chan HYL, Choi KC, Wan RWM, Mak SSS, Chair SY \& Chan CWH. Quality of life and most prevalent unmet needs of Chinese breast cancer survivors at one year after cancer treatment. Eur J Oncol Nurs. 2014; 18 (3): 323-328.

[18] Han Y, Zhou Y, Wang J, Hall A, Zhao Q, Qin H, Fan Y, Song $\mathrm{Y} \&$ Cui S. Chinese version of the Cancer Support Person's Unmet Needs Survey-Sort Form: A psychometric study. Eur J Cancer Care (Engl). 2019; 28 (2): e12963.

[19] Xing W, So WKW, Choi KC, Wong CL, Tong M, Choy YP, Molassiotis A, Yates $P$ \& Chan RJ. Translation and psychometric testing of Cancer Survivors' Unmet Needs, Chinese version. Asia Pac J Clin Oncol. 2019; 15 (5): e142e146. 
[20] Li M, Wang Y \& Xie H. [The status of the spiritual nursing needs of cancer patients and its influencing factors]. Chinese $J$ Nurs. 2017; 52 (08): 930-934.

[21] Li H, Lu Q \& Yang P. [A study on the symptoms and continuing care needs of PHC patients]. Chinese J Nurs. 2015; 50 (06): 684-688.

[22] Koshimoto S, Arimoto M, Saitou K, Uchibori M, Hashizume A, Honda A, Amano K, Nakajima Y, Uetake H \& Matsushima E. Need and demand for nutritional counselling and their association with quality of life, nutritional status and eating-related distress among patients with cancer receiving outpatient chemotherapy: a cross-sectional study. Support Care Cancer. 2019; 27 (9): 3385-3394.

[23] Kent EE \& Dionne-Odom JN. Population-based profile of mental health and support service need among family caregivers of adults with cancer. J Oncol Pract. 2019; 15 (2): E122-E131.

[24] You C, Zhang C \& Mingjun Z. [A qualitative study on the experience of care load of the main caregivers of advanced cancer patients in Xinjiang]. China Med Her. 2018; 15 (20): $39-42+46$.

[25] Ferlay J, Soerjomataram I, Dikshit R, Eser S, Mathers C, Rebelo M, Parkin DM, Forman D \& Bray F. Cancer incidence and mortality worldwide: Sources, methods and major patterns in GLOBOCAN 2012. Int $J$ Cancer. 2015; 136 (5): E359E386.

[26] M. C. K, C. A. W. B, I. M, R. A. W, I. M. K \& L. L. Psychometric properties of the Dutch extended Cancer
Survivors' Unmet Needs measure (CaSUN-NL). Eur J Cancer Care (Engl). 2018; 27 (2): e12807.

[27] Shi J, Mo X \& Sun Z. [Content validity index in scale development]. Zhong Nan Da Xue Xue Bao Yi Xue Ban. 2012; 37 (2): $152-5$.

[28] Ursachi G, Horodnic IA \& Zait A. How Reliable are Measurement Scales? External Factors with Indirect Influence on Reliability Estimators. Procedia Econ Financ. 2015; 20679-686.

[29] Afiyanti Y, Gayatri D, Besral \& dan Haryani. Unmet supportive care needs of Indonesian gynecological cancer survivors. Enfermería Clínica. 2019; 29869-873.

[30] Giuliani M, Papadakos J, Broadhurst M, Jones J, McQuestion M, Le LW, Beck L, Waldron J \& Ringash J. The prevalence and determinants of return to work in head and neck cancer survivors. Support Care Cancer. 2019; 27 (2): 539-546.

[31] Russell L, Gough K, Drosdowsky A, Schofield P, Aranda S, Butow PN, Westwood JA, Krishnasamy M, Young JM, Phipps-Nelson J, King D \& Jefford M. Psychological distress, quality of life, symptoms and unmet needs of colorectal cancer survivors near the end of treatment. J Cancer Surviv. 2015; 9 (3): $462-470$

[32] Chung J, Kulkarni GS, Morash R, Matthew A, Papadakos J, Breau RH, Guttman D, Bender J \& Jones JM. Assessment of quality of life, information, and supportive care needs in patients with muscle and non-muscle invasive bladder cancer across the illness trajectory. Support Care Cancer. 2019; 27 (10): 3877-3885. 